\title{
International Space Station Carbon Dioxide Removal Assembly Testing
}

James C. Knox NASA Marshall Space Flight Center 
SAE routinely stocks printed papers for a period of three years following date of publication. Direct your orders to SAE Customer Sales and Satisfaction Department.

Quantity reprint rates can be obtained from the Customer Sales and Satisfaction Department.

To request permission to reprint a technical paper or permission to use copyrighted SAE publications in other works, contact the SAE Publications Group.

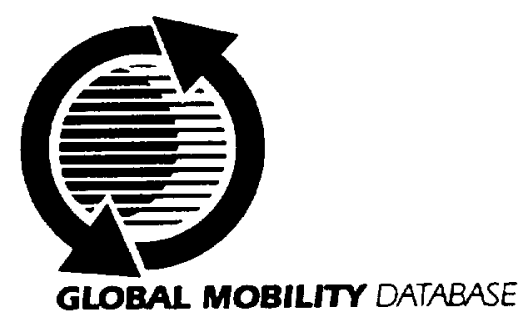

All SAE papers, standards, and selected books are abstracted and indexed in the Global Mobility Database

ISSN 0148-7191

Positions and opinions advanced in this paper are those of the author(s) and not necessarily those of SAE. The author is solely responsible for the content of the paper. A process is available by which discussions will be printed with the paper if it is published in SAE Transactions. For permission to publish this paper in full or in part, contact the SAE Publications Group.

Persons wishing to submit papers to be considered for presentation or publication through SAE should send the manuscript or a 300 word abstract of a proposed manuscript to: Secretary, Engineering Meetings Board, SAE.

\section{Printed in USA}




\title{
International Space Station Carbon Dioxide Removal Assembly Testing
}

\author{
James C. Knox \\ NASA Marshall Space Flight Center
}

Copyright $@ 2000$ Society of Automotive Engineers, Inc.

\begin{abstract}
Performance testing of the International Space Station Carbon Dioxide Removal Assembly flight hardware in the United States Laboratory during 1999 is described. The CDRA exceeded carbon dioxide performance specifications and operated flawlessly. Data from this test is presented.
\end{abstract}

\section{INTRODUCTION}

This paper reports the Carbon Dioxide Removal Assembly (CDRA) and Atmosphere Revitalization System (ARS) testing performed at Kennedy Space Center in support of the International Space Station program. The specific test discussed is the Closed Hatch Environmental Control and Life Support System (ECLSS) Qualification test. The test article is the US Laboratory (USL), to be launched on assembly flight 5A. Closed Hatch ECLSS (CHE) Qualification testing was conducted in April and May of 1999.

The CDRA is described first, as the primary subject of this paper. The overall Atmosphere Revitalization Subsystem will be described with respect to functionality, connectivity, and interfaces with other subsystems.

The test configuration of the US Lab as it relates to the ARS operation will be described. Support equipment used during the CHE Qualification Test will be identified. The test objectives and operational steps will be outlined. Finally, test data pertaining to ARS operations will be presented and conclusions drawn.

\section{CDRA DESCRIPTION}

As show in Figure 1, the CDRA is tightly integrated and mounted on slides for installation in the Atmosphere Revitalization System rack. Air selector valves are visibly numbered 101 through 106 . The blower and precooler orbital replacement unit (ORU) is visible in the right center section of the drawing. Process air and coolant water interfaces are on the lower right of the drawing.
The sorbent beds are not clearly visible, but are behind the valves and tubing. Controllers for the bed heaters, air-save pump, and blower are on the left side, identified by the many electrical connectors. The air-save pump resides below the controllers.

The operation of the CDRA can be explained with the aid of the schematic shown in Figure 2. The CDRA continuously removes carbon dioxide $\left(\mathrm{CO}_{2}\right)$ from the ISS atmosphere. The four beds consist of two desiccant beds and two $\mathrm{CO}_{2}$ sorbent beds. The system operates such that one desiccant bed and one $\mathrm{CO}_{2}$ sorbent bed are adsorbing while the other two beds are desorbing. When a new half cycle begins, the beds switch sorbent modes. The incoming air stream to the CDRA is downstream of a condensing heat exchanger, and has a dewpoint and drybulb temperature of 4.4 to $10^{\circ} \mathrm{C}(40$ to $50^{\circ} \mathrm{F}$ ) ${ }^{1}$. The air stream passes first through a desiccant bed to remove much of the moisture from the process air. The temperature of the air stream rises as it flows through the desiccant bed due to the heat of adsorption. The process air is then drawn through the system blower and then through an air-liquid heat exchanger or precooler. The precooler increases $\mathrm{CO}_{2}$ sorbent efficiency by reducing process air temperature before entering the $\mathrm{CO}_{2}$ sorbent bed. Prior to returning to the cabin, the air stream passes through the desiccant bed that adsorbed moisture from the previous half cycle. The wet desiccant bed desorbs this moisture to the air stream and returns it to the cabin atmosphere. This is called a water-save system, in contrast to the 2-bed Skylab system, which vented adsorbed water to space.

The alternate $\mathrm{CO}_{2}$ sorbent bed desorbs by heating with integral electrical heaters and application of space vacuum or, for ground testing, a simulated space vacuum. The heat supplied by the electrical heaters serve two purposes; it breaks the bond the $\mathrm{CO}_{2}$ has with the sorbent material, and in the subsequent half-cycle heats the passing air-stream to dry out the desorbing desiccant bed. For the first 15 minutes of each half-cycle, the air-save pump operates to remove residual air from the desorbing sorbent bed and returns it to the cabin. 


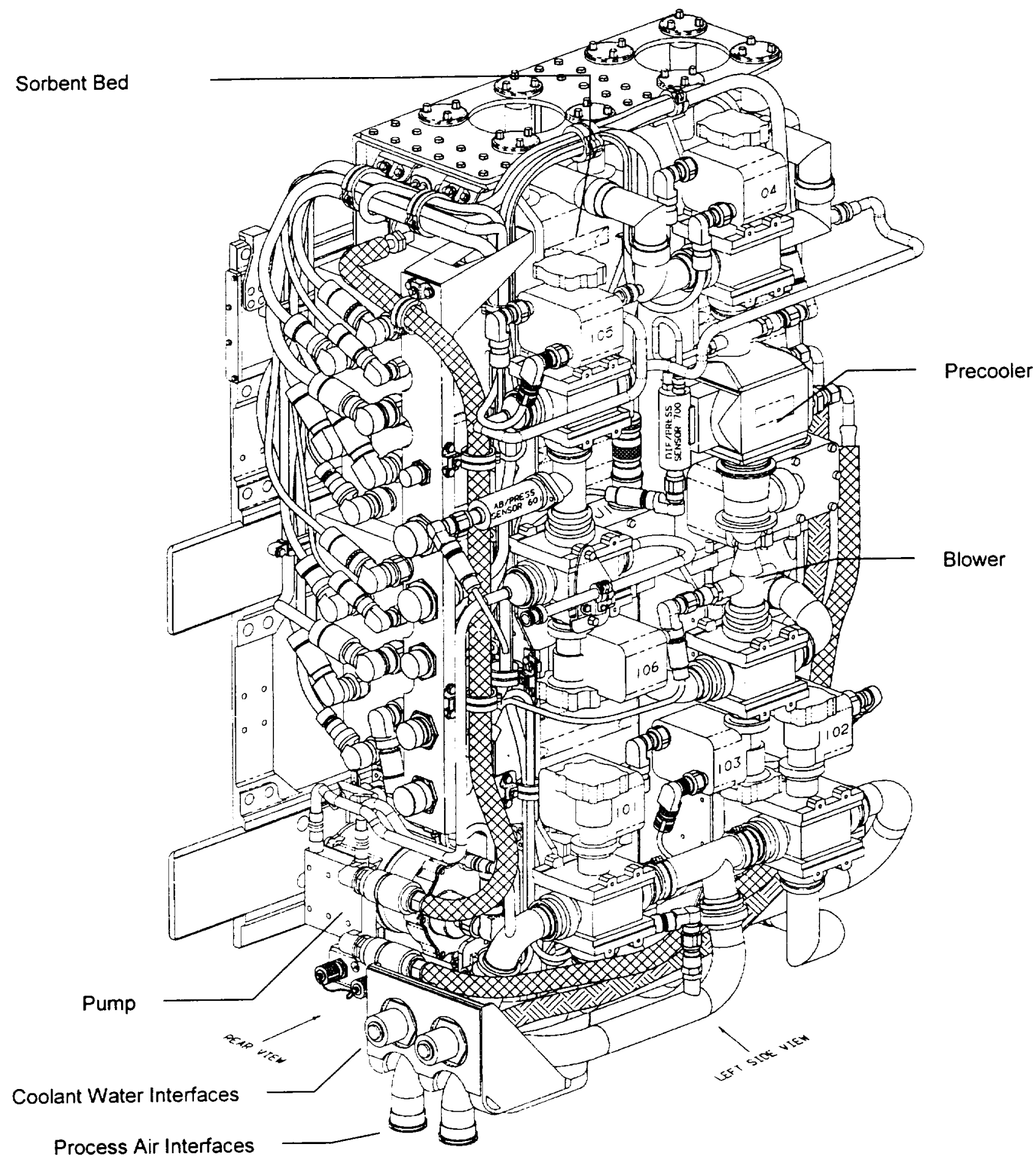

Figure 1. CDRA Flight Hardware

\section{AR SUBSYSTEM DESCRIPTION}

In Figure 3, the CDRA can be seen installed into the AR rack. Other major assemblies visible are the Trace Contaminant Control Subassembly (TCCS) and the
Major Constituent Analyzer (MCA). Although not reported on specifically here, both the TCCS and MCA were also operated successfully during CHE testing. The MCA was used to measure $\mathrm{CO}_{2}$ concentration and provided data for $\mathrm{CDRA} \mathrm{CO}_{2}$ removal performance. 


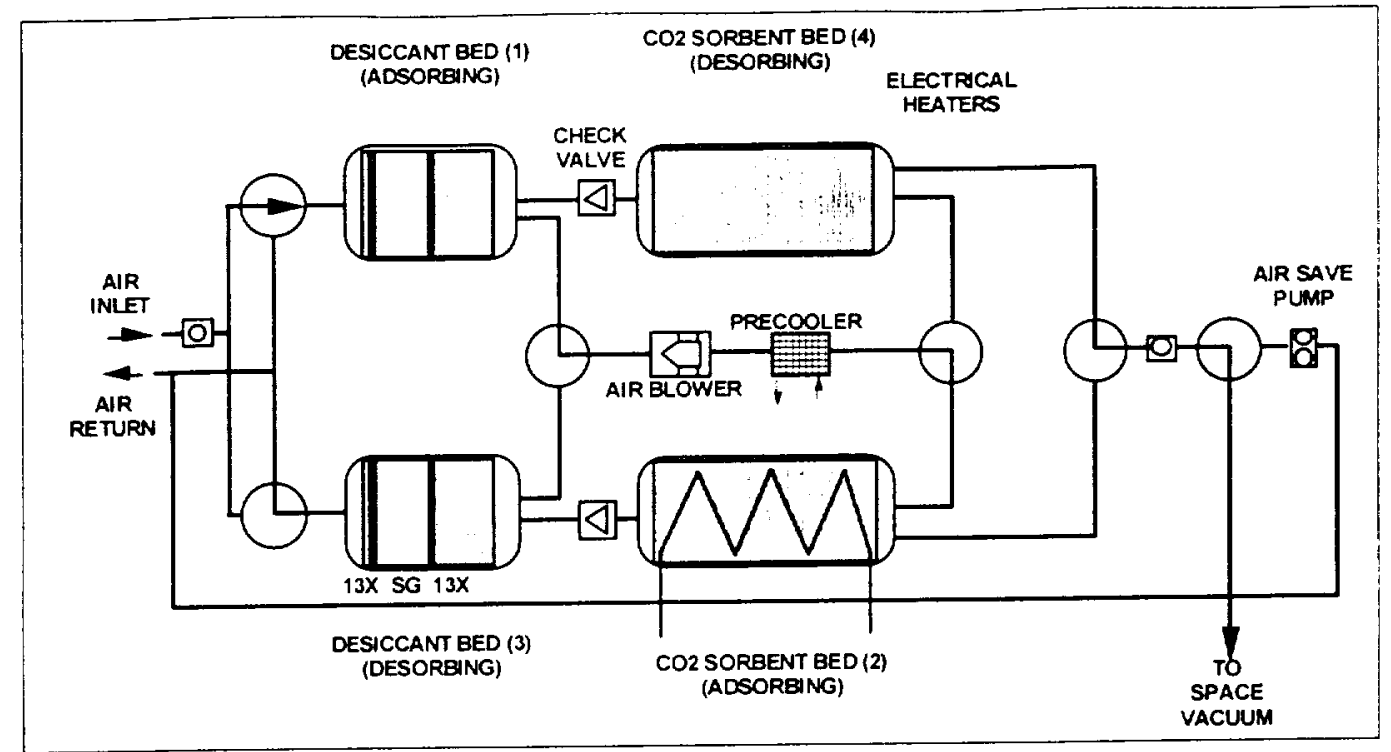

Figure 2. CDRA Schematic

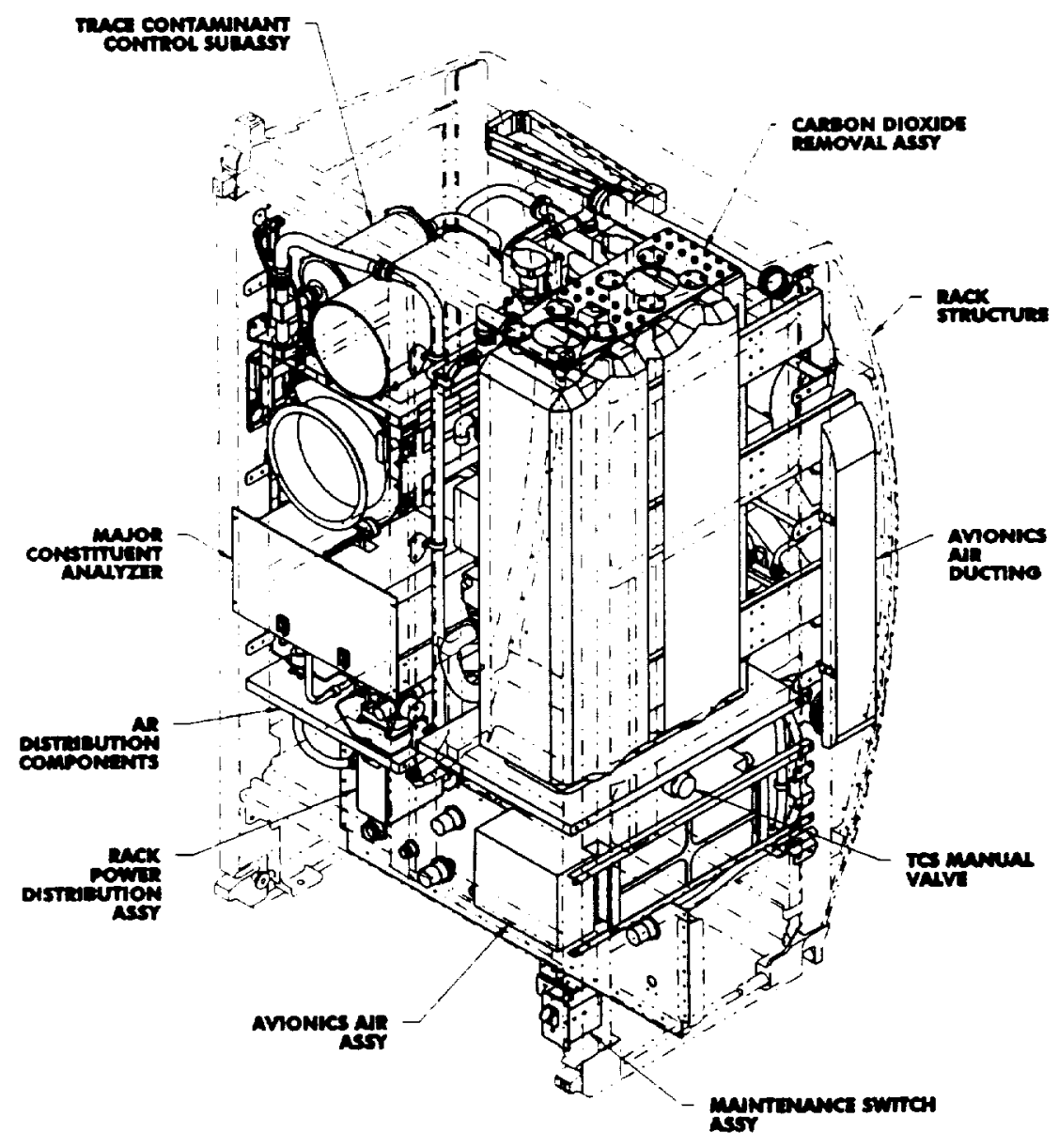

AR RACK FRONT ISOMETRIC VIEW

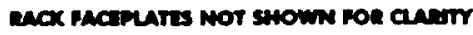

Figure 3. Atmosphere Revitalization Rack' 
AR subsystem interfaces are shown in Figure 4. Interfaces between AR rack components are limited to Avionics Air Assembly (AAA) cooling of the MCA, sampling of the TCCS process air by the MCA, and combining the CDRA and TCCS outlet air streams (not shown). Interfaces between the AR rack and other US Laboratory interfaces are more extensive, including Lab air to the TCCS, Temperature and Humidity Control (THC) supply air to the CDRA, and Internal Thermal Control System (ITCS) cooling water to the CDRA and AAA. Selected interfaces are described in more detail below.

\section{U.S. LABORATORY INTERFACES}

AR rack location and distributed AR hardware in the U.S. Lab are shown in Figure 5. The CDRA inlet air is supplied via a dedicated line, tapping into the outlet of the common cabin air assembly (CCAA) condensing heat exchanger. This location provides cool air of low humidity, enabling higher CDRA performance. The process air line is connected to both CCAA units, only one of which is operational at one time. A process air valve selects the active CCAA.

Carbon dioxide is vented overboard via a dedicated 1.27 $\mathrm{cm}$ ( $1 / 2$ inch) line. Two $\mathrm{CO}_{2}$ vent valves (one shown, one located inside the AR rack) are closed during CDRA nonoperational periods. The valves close in the case of power failure to prevent loss of atmosphere to space vacuum.

Other AR hardware items shown are the air sample lines, valves, and ports. The sample port shown supplied air to the MCA for the purpose of measuring the Lab atmosphere during $\mathrm{CHE}$ testing. Samples lines will be used in orbit to sample the atmosphere in other modules.

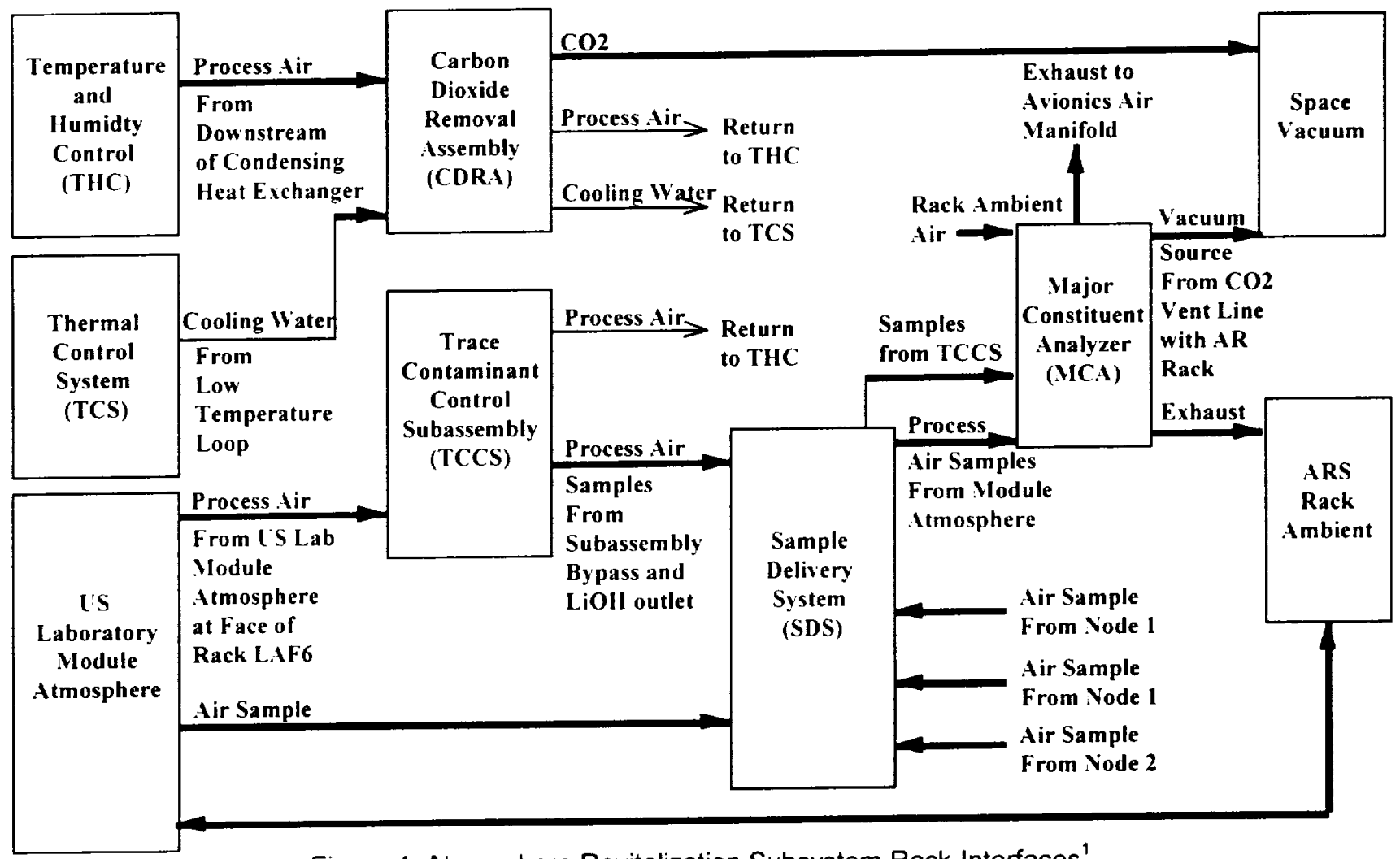

Figure 4. Atmosphere Revitalization Subsystem Rack Interfaces ${ }^{1}$

\section{TEST PURPOSE}

The Closed Hatch ECLSS test was conducted as a qualification test of three ECLS subsystems, including the Temperature and Humidity Control Subsystem, the Atmosphere Control and Supply (ACS) Subsystem, and the Atmosphere Revitalization Subsystem. Testing was conducted at Kennedy Space Center from April 30 through May 8 , and was comprised of a series of test cases performed with a range of loading conditions and control variable setpoints.
$\mathrm{CO}_{2}$ injection rates, humidity injection rates, and sensible heat loads were varied to simulate varying crew metabolic loads and other on-orbit variations. Oxygen removal was active only during ACS performance testing.

Internal Temperature Control Subsystem (ITCS) coolant setpoints (both moderate and low temperature loops) were varied at the limits of their specification ranges. Cabin temperature and pressure setpoints were also varied. Details of each test case can be seen in Table 1. 


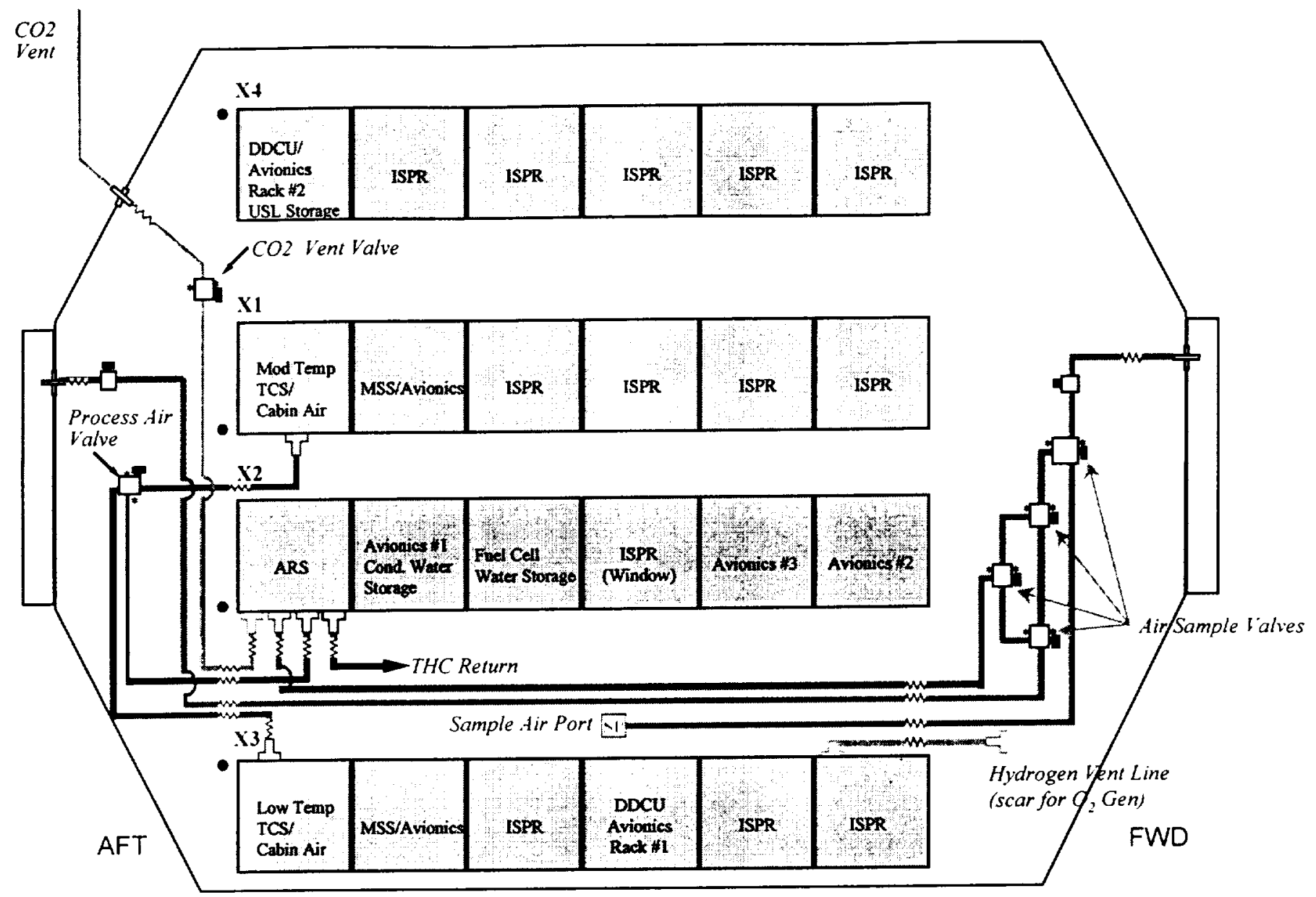

Figure 5. U.S. Laboratory Atmosphere Revitalization Schematic ${ }^{2}$

Table 1. Closed Hatch ECLSS Qualification Test Cases ${ }^{2}$

\begin{tabular}{|c|c|c|c|c|c|c|c|}
\hline \multicolumn{8}{|c|}{ CLOSED-HATCH ECLSS QUALIFICATION TEST CASES } \\
\hline & \multicolumn{7}{|c|}{ Control Variables } \\
\hline & \multicolumn{2}{|c|}{$\begin{array}{l}\text { Coolant Temp } \\
\text { Setpoints }\end{array}$} & \multirow{2}{*}{$\begin{array}{l}\mathrm{CO}_{2} \\
\text { Load } \\
\mathrm{b} / \mathrm{day} \\
\end{array}$} & \multirow{2}{*}{$\begin{array}{c}\text { Latent } \\
\text { Load } \\
\text { Ib/day } \\
\end{array}$} & \multirow{2}{*}{$\begin{array}{c}\begin{array}{c}\text { Sensible } \\
\text { Load }\end{array} \\
\mathrm{W} \\
\end{array}$} & \multirow{2}{*}{$\begin{array}{l}\begin{array}{c}\text { Cabin Temp } \\
\text { Setpoint }\end{array} \\
{ }^{\circ} \mathrm{F} \\
\end{array}$} & \multirow{2}{*}{$\begin{array}{c}\text { Cabin } \\
\text { Pressure } \\
\text { Setpoint } \\
\text { psia } \\
\end{array}$} \\
\hline Test Cases & LTL & MTL & & & & & \\
\hline \multicolumn{8}{|c|}{ Test Case 1, Preconditioning of Module } \\
\hline Condition 1, CDRA Dryout & $\begin{array}{l}40^{\circ} \mathrm{F} \\
(+3 / 2) \\
\end{array}$ & $63^{\circ} \mathrm{F}( \pm 2)$ & 13.2 & 12 & $1750( \pm 100)$ & $72( \pm 3)$ & 14.9 \\
\hline \multicolumn{8}{|c|}{ Test Case 3, $\mathrm{CO}_{2}$ Removal Performance } \\
\hline Condition 1 A, High Moisture & $\begin{array}{l}40^{\circ} \mathrm{F} \\
(-3 /-2)\end{array}$ & $\begin{array}{l}65^{\circ} \mathrm{F} \\
(+0 /-4)\end{array}$ & 13.2 & 12 & $\begin{array}{l}2885 \\
(+100 / .0) \\
\end{array}$ & $65(4)$ & 14.9 \\
\hline Condition IB, High $\mathrm{CO}_{2}$ Load & $\begin{array}{l}43^{\circ} \mathrm{F} \\
(+0)-5) \\
\end{array}$ & $\begin{array}{l}61^{\circ} \mathrm{F} \\
(+4 /(-)) \\
\end{array}$ & 13.2 & 12 & $940(+0 /-100)$ & $65( \pm 3)$ & 14.9 \\
\hline Condition 2, Medium CO: Load & $\begin{array}{l}43^{\circ} \mathrm{F}(-(1)) \\
51\end{array}$ & $\begin{array}{l}61^{\circ} \mathrm{F} \\
(+4 /(-0) \\
\end{array}$ & 8.8 & 12 & $940(+0 /-100)$ & $65( \pm 3)$ & 14.9 \\
\hline Condition 3, Low $\mathrm{CO}_{2}$ Load & $\begin{array}{l}43^{\circ} \mathrm{F} \\
(+0)-51\end{array}$ & $\begin{array}{l}61^{\circ} \mathrm{F} \\
(+4 /-0)\end{array}$ & 6.6 & 12 & $940(+0)-100)$ & $65( \pm 3)$ & 14.9 \\
\hline
\end{tabular}




\section{TEST SETUP}

When in orbit, the USL will obtain power from solar panels, cooling from the ISS radiators, and have access to the vacuum of space. For ground testing of the Lab. various support equipment was required to provide, for example, power, data interfaces, cooling water, a vacuum source, and simulation of crew metabolic loading. Selected interfaces are shown in Figure 6 below. Supporting equipment critical to qualification testing of the CDRA are discussed below.

\section{METABOLIC SIMULATOR}

In order to test the $\mathrm{CO}_{2}$ removal capability of the $\mathrm{CO}_{2}$ removal assembly, simulation of the crew metabolic $\mathrm{CO}_{2}$ production was required. The CHE Qualification Test Readiness Review (TRR) documentation provides the following description ${ }^{2}$ :

Simulates the principal metabolic functions of up to a sixperson crew, worst-case animal and biological contributions, and total sensible heat loads.

Specific functions include:

- $\mathrm{CO}_{2}$ introduction into the USL via a $\mathrm{CO}_{2}$ doser and monitor.

- $\mathrm{O}_{2}$ removal from the USL via an off-the-shelf $\mathrm{O}_{2}$ concentrator and monitor.

- Airborne sensible heat introduction into the USL via heaters and temperature sensors.

- Humidity introduction into the USL via an ultrasonic humidifier and a dewpoint sensor.

\section{VACUUM SYSTEM}

As shown in Figure 5, the CDRA has a dedicated $\mathrm{CO}_{2}$ vent line, which will vent to space vacuum when the USL is in orbit. An accumulator, roughing pump and turbo pump provided a simulated space vacuum for USL CHE Qualification testing. A four-inch duct was provided as input to the accumulator. Pressure measurements were taken inside the $1 / 2$ inch $\mathrm{CO}_{2}$ vent line and the 4 inch duct to insure that choked flow was achieved during $\mathrm{CO}_{2}$ desorption.

\section{TEST HATCH}

In order to maintain a closed environment inside the USL and provide the required support equipment interfaces, a test hatch was designed and built. As described in the CHE Qualification Test Readiness Review ${ }^{2}$ :

SK683-53277-1. Test Hatch, provides fluid and electrical feedthroughs for support equipment interfaces to the internal USL.
- Fluid Interfaces include:

- ITCS supply and return hoses for FE 1247-1 top, middle, and bottom units of Carts 2 and 3

- $7 \mathrm{CO}_{2}$ sample ports, $1 \mathrm{CO}_{2}$ return port, and 1 $\mathrm{CO}_{2}$ insertion port

- Oxygen Removal port (from oxygen concentrator in USL).

- Water insertion port (to ultrasonic humidifier in USL).

- FE 1401 nitrogen insertion port.

- Electrical Interfaces include:

- 1 port for FE 1247-1 (Carts 2 \& 3) RTDs and dP sensors.

- 7 ports for FE 1413 auxiliary instrumentation.

- 3 ports for FE 1243 :

- Oxygen concentrator.

- Strip heaters and ultrasonic humidifier.

- Instrumentation

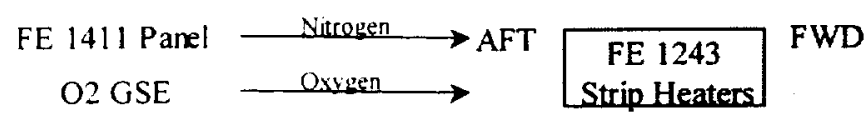

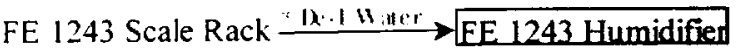

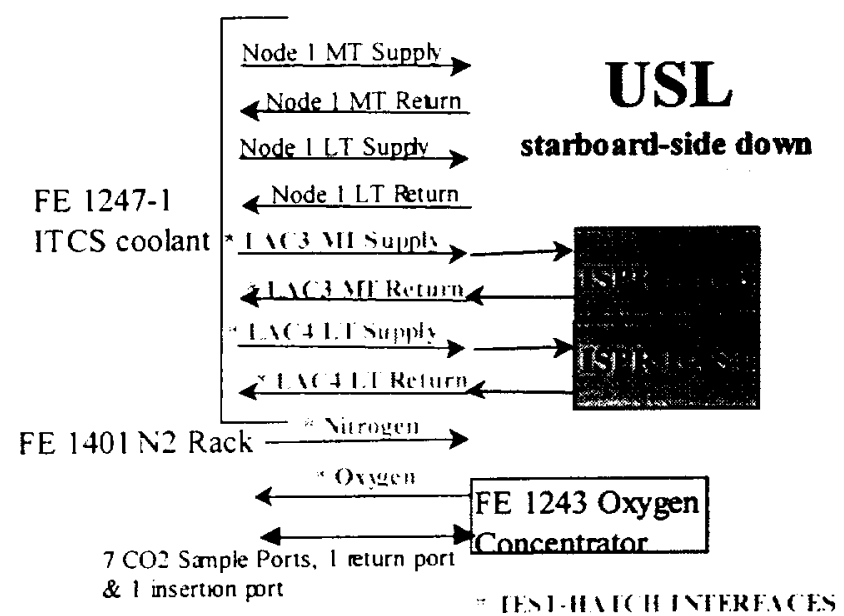

Figure 6. Supporting Equipment Interfaces ${ }^{2}$

\section{TEST DUCTS}

One objective of the USL CHE Qualification Test was to measure the flow rate of the CDRA integrated with the CCAA. To this end, test ducts were constructed using a modified pitot-type tube and pressure measurements to derive mass flow rate.

\section{TEST PROCEDURE AND CONDUCT}

\section{TEST CASE 1, CONDITION 1, CDRA DRYOUT AND PROCESS AIR FLOWRATE CHECKOUT}

The USL CHE Qualification Test consisted of numerous conditions, a subset of which is shown in Table 1. The first test case was to both ensure dryout of the CDRA 
and set CDRA process air at the desired flowrate. Dryout is performed for 24 hours with the sorbent bed heater setpoint at $204^{\circ} \mathrm{C}\left(400^{\circ} \mathrm{F}\right)$ as opposed to the $127^{\circ} \mathrm{C}$ $\left(260^{\circ} \mathrm{F}\right)$ setpoint used for normal operating mode, otherwise known as power-save mode. Dryout was required here to insure previous AR rack standalone testing with ambient inlet air would not adversely effect $\mathrm{CO}_{2}$ removal performance.

The initial blower speed was 115,000 RPM and provided a flowrate of $39 \mathrm{~kg} / \mathrm{hr}(86.5 \mathrm{lb} / \mathrm{hr})$, averaged over a full cycle or 288 minutes. Since a flow rate greater than 41 $\mathrm{kg} / \mathrm{hr}(90 \mathrm{lb} / \mathrm{hr})$ was required to insure adequate $\mathrm{CO}_{2}$ removal performance, the blower speed was then increased to 120,000 RPM. For this blower speed, average flowrate over the next three cycles was 42.7 $\mathrm{kg} / \mathrm{hr}(94.1 \mathrm{lb} / \mathrm{hr})$, well above the minimum.

The exit process air of the TCCS at $0.9 \mathrm{~kg} / \mathrm{hr}(2 \mathrm{lb} / \mathrm{hr})$ joins that of the CDRA prior to dumping into the CCAA return line. To insure operation of the TCCS does not affect CDRA flowrate, the TCCS was started and the process air flowrate re-measured. The resulting value was $42.3 \mathrm{~kg} / \mathrm{hr}(93.3 \mathrm{lb} / \mathrm{hr})$, still well above the $90 \mathrm{lb} / \mathrm{hour}$ minimum. Note that there is a large difference in flow rate, averaging about $2.7 \mathrm{~kg} / \mathrm{hr}(6 \mathrm{lb} / \mathrm{hr})$, between halfcycle 1 and 2 . This may to be due to the blower setting up a rotation in the flow. Resistance to flow would then depend on the position of valve 104 and thus the direction of the $90^{\circ}$ bend. Valve 104 selects the proper sorbent bed for the current half-cycle.

\section{TEST CASE $3, \mathrm{CO}_{2}$ REMOVAL PERFORMANCE}

CDRA performance was measured during this test case Results are shown in Figure 7. Two methods of $\mathrm{CO}_{2}$ partial pressure measurement were employed. A Horiba VIA-510 Dual Beam Non-Dispersive Infrared (NDIR) analyzer was obtained for high repeatability $(0.5 \%$ full scale specification). This was employed to measure both CDRA $\mathrm{CO}_{2}$ removal performance and verify MCA accuracy. However, levels were much lower than expected (see the "Raw Horiba" trace in Figure 7). After extensive troubleshooting, it was determined that the calibration gases procured for the Horiba analyzer were incorrectly mixed. Post-test calibration of the Horiba analyzer provided a near-linear correction factor ${ }^{3}$. As shown, the MCA and Horiba are in close agreement following correction (see "Corrected Horiba"). $\mathrm{CO}_{2}$ requirement levels are determined by the equation below :

$$
p p C O 2=(H E U+0.7085) / 1.723
$$

where, $\mathrm{HEU}=$ metabolic $\mathrm{CO}_{2}$ generation rate for one person $\left(2.2 \mathrm{lb} /\right.$ dy $\left.\mathrm{CO}_{2}\right)$

$\mathrm{ppCO}_{2}=$ Carbon Dioxide partial pressure in the Lab atmosphere, torr

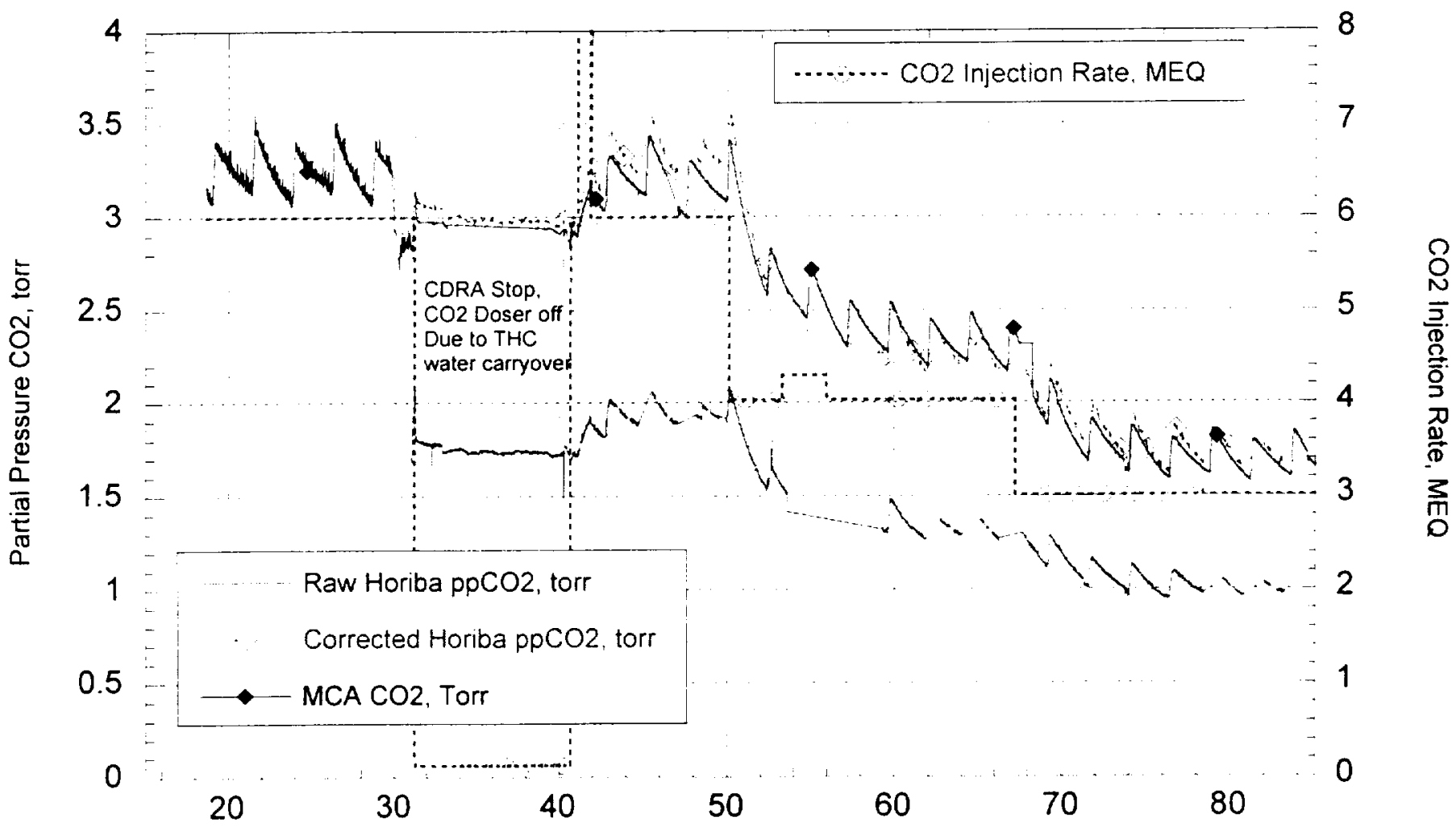

Elapsed Time, Hours from GMT 123 00:00:00

Figure 7. Cabin $\mathrm{CO}_{2}$ Levels for Test Case 3 
Test Case 3. Condition $1 \mathrm{~B}$. High $\mathrm{CO}_{2}$ Load

CDRA CO2 removal performance was measured in Conditions $1 \mathrm{~B}, 2$, and 3 , with varying $\mathrm{CO} 2$ injection rates. The first condition was with $\mathrm{CO} 2$ injection rate set at the metabolic equivalent of six crewmembers, or $6 \mathrm{~kg} / \mathrm{dy}$ (13.2 lb/dy). Cabin CO2 partial pressure levels for this condition are shown in Figure 8 . Sequential half-cycles are indicated by numbers in circles.

At approximately 31 hours elapsed time, the CCAA experienced a water carry-over event. The CDRA and $\mathrm{CO} 2$ doser were shutdown for nearly 10 hours. Following restart, $\mathrm{CO} 2$ injection levels were increased temporarily to restore the concentration level. Since the preshutdown concentration was not actually restored, halfcycles 53 through 56 were used to calculate CDRA removal performance.

Horiba data was not available for these half-cycles. This analyzer was configured to sample CDRA inlet and outlet streams as well as three cabin air locations. Gaps in the cabin Horiba data occur during for periods when valves were configured to sample alternate locations. To provide an estimate of Horiba measured concentration for half-cycles 53 to 56 , values for half-cycles 59 through 60 were compared with MCA values, yielding a constant Horiba offset of 0.12 torr.
Test Case 3, Condition 2, Medium $\mathrm{CO}_{2}$ Load

For the medium $\mathrm{CO} 2$ load case, the injection rate was to be equivalent to a four person loading, or $4 \mathrm{~kg} / \mathrm{dy}(8.8$ $\mathrm{lb} / \mathrm{hr})$. Actual injection rate was $8.87 \mathrm{lb} / \mathrm{hr}$. Cabin CO2 partial pressure levels for this condition are shown in Figure 9. The MCA and Horiba values are in close agreement, and well below the requirement. $A$ comparison of MCA and Horiba values for half-cycle 66 yields an Horiba offset of -0.03 torr. Half-cycles 67 and 68 were used to calculate CDRA removal performance. Results for this case are conservative, since steady-state cabin levels are not quite achieved.

\section{Test Case 3, Condition 3, Low $\mathrm{CO}_{2}$ Load}

For the low $\mathrm{CO} 2$ load case, the injection rate was equivalent to a 3 person loading, or $3 \mathrm{~kg} / \mathrm{dy}(6.6 \mathrm{lb} / \mathrm{hr})$. Cabin $\mathrm{CO} 2$ partial pressure levels for this condition are shown in Figure 10 . Once again the MCA and Horiba values are in close agreement, and well below the requirement. Half-cycles 75 through 78 were used to calculate $\mathrm{CO} 2$ removal performance. Comparison of MCA and Horiba values during half-cycle 72 yielded an offset of 0.03 torr.

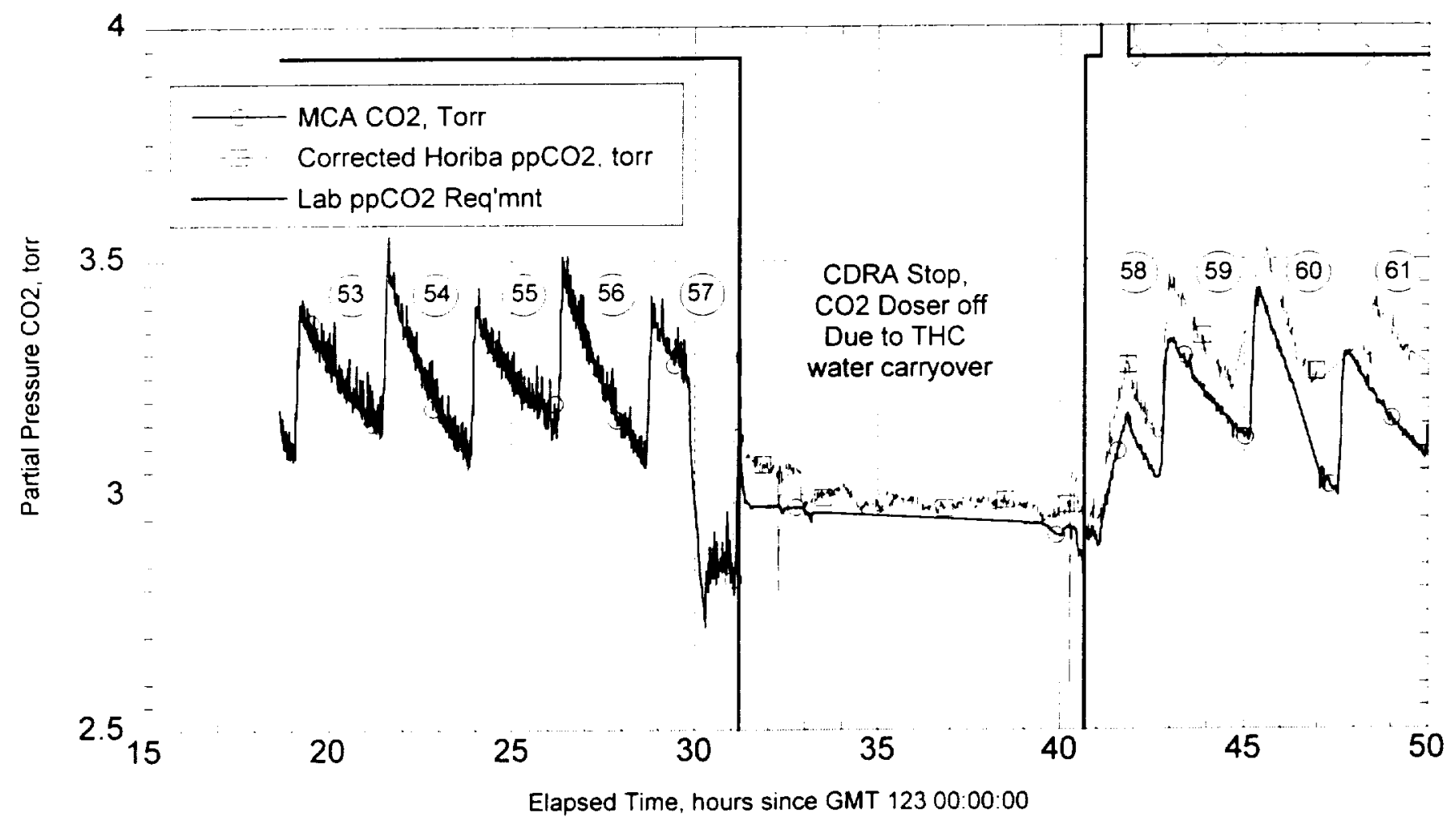

Figure 8. Cabin $\mathrm{CO}_{2}$ Levels for High $\mathrm{CO}_{2}$ Loading 


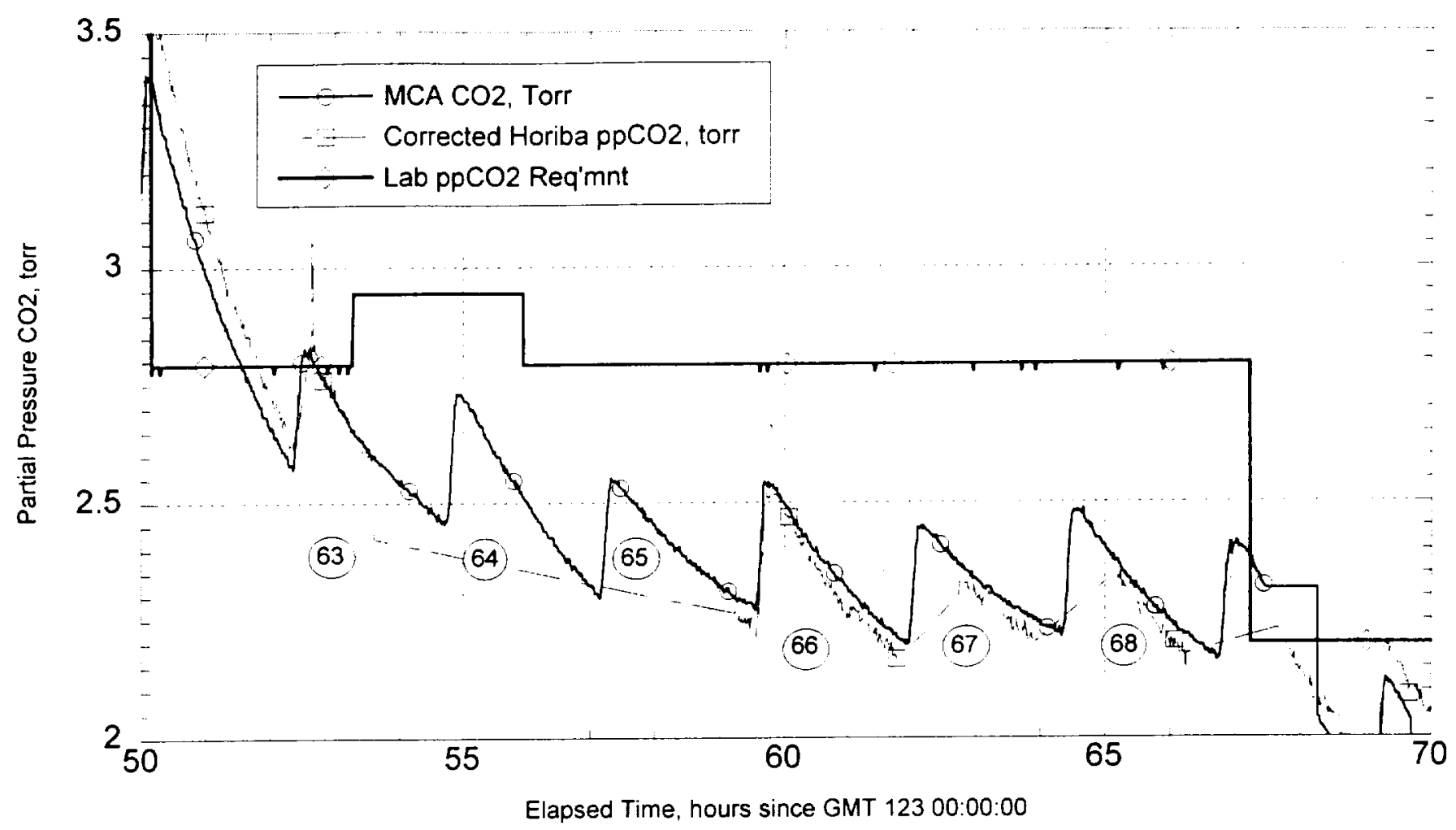

Figure 9. Cabin $\mathrm{CO}_{2}$ Levels for Medium $\mathrm{CO}_{2}$ Loading
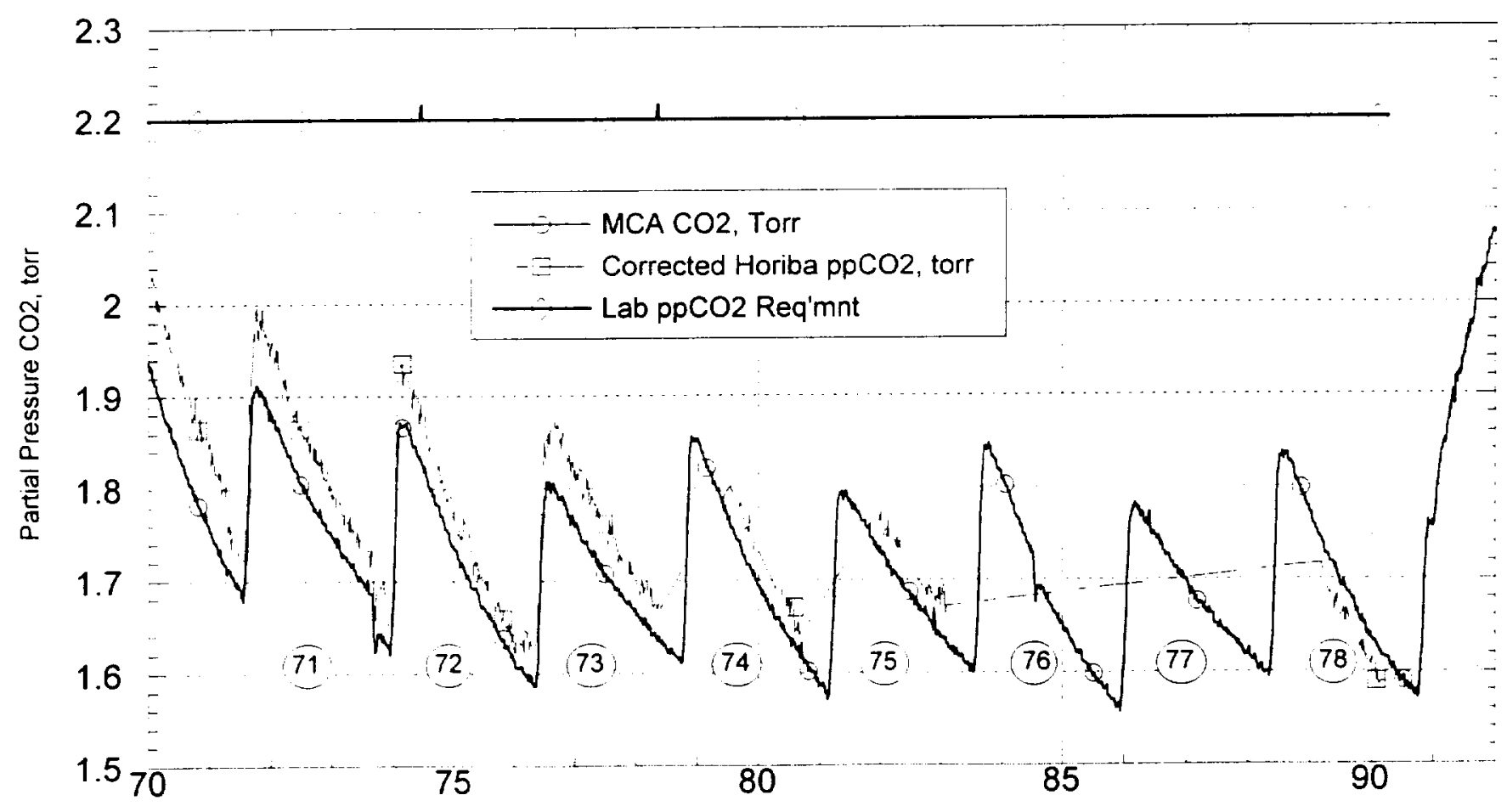

Elapsed Time, hours since GMT 123 00:00:00

Figure 10. Cabin $\mathrm{CO}_{2}$ Levels for Low $\mathrm{CO}_{2}$ Loading 


\section{RESULTS}

Average $\mathrm{CO}_{2}$ partial pressure for each half-cycle used to evaluate $\mathrm{CO}_{2}$ removal performance is shown in Table 1 . Also shown, for comparison, are values from a Boeing Product Group Three analysis of the test data ${ }^{5}$. The primary variation in the data is in the "Required $\mathrm{ppCO}_{2}{ }^{n}$ column, due to use of different calibration curve for the $\mathrm{CO}_{2}$ doser. A later calibration performed by Marshall Space Flight Center Calibration Facility was used for this analysis ${ }^{6}$.

A simplistic error analysis is illustrated in Figure 11 and Figure 12. Manufacturers advertised accuracy is used to provide error bars for the data shown in Table 2. Horiba analyzer accuracy error is the most conservative at $+/$ $1.5 \%$ of full scale. This error includes interference with coexisting gases, repeatability, normal zero and span drift, line voltage variability, and sample flow rate variation ${ }^{3}$. Actual accuracy is most likely higher. $\mathrm{CO}_{2}$ Doser accuracy error is based on bias accuracy of the calibration device, or $+1-0.35 \%$ of reading ${ }^{7}$. Observation of test data indicated minimal drift, so bias error is probably dominant. MCA accuracy error is based on the requirement of $3 \%$ of full scale'. Again, actual accuracy is expected to be significantly better.

Table 2. Average $\mathrm{CO}_{2}$ Partial Pressures

\begin{tabular}{|c|c|c|c|c|c|c|}
\hline $\begin{array}{l}\frac{T}{D} \\
\frac{0}{\bar{\phi}} \\
\hat{\infty} \\
\frac{1}{D}\end{array}$ & 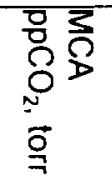 & 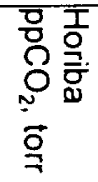 & 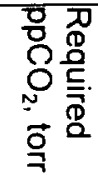 & 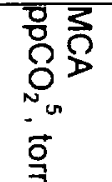 & 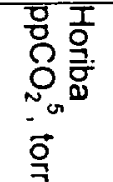 & 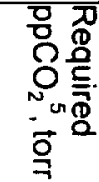 \\
\hline \multicolumn{7}{|c|}{ Test Condition 1B (6 Crew Equivalent) } \\
\hline 53 & 3.26 & & 3.93 & & & \\
\hline 54 & 3.25 & & 3.93 & & & \\
\hline 55 & 3.25 & & 3.93 & & & \\
\hline 56 & 3.24 & & 3.93 & & & \\
\hline $53-56$ & 3.25 & 3.35 & 3.93 & 3.285 & 3.385 & 3.843 \\
\hline $59-60$ & 3.22 & 3.34 & 3.93 & & & \\
\hline \multicolumn{7}{|c|}{ Test Condition 2 (4 Crew Equivalent) } \\
\hline 66 & 2.34 & 2.37 & 2.79 & & & \\
\hline 67 & 2.32 & & 2.79 & & & \\
\hline 68 & 2.31 & & 2.79 & & & \\
\hline $67-68$ & 2.32 & 2.29 & 2.79 & 2.285 & 2.305 & 2.724 \\
\hline \multicolumn{7}{|c|}{ Test Condition 3 (3 Crew Equivalent) } \\
\hline 72 & 1.72 & 1.75 & 2.2 & & & \\
\hline 73 & 1.72 & & 2.2 & & & \\
\hline 74 & 1.70 & & 2.2 & & & \\
\hline 75 & 1.69 & & 2.2 & & & \\
\hline $74-75$ & 1.70 & 1.73 & 2.2 & 1.71 & 1.74 & 2.152 \\
\hline 76 & 1.69 & & 2.2 & & & \\
\hline 77 & 1.68 & & 2.2 & & & \\
\hline 78 & 1.69 & & 2.2 & & & \\
\hline $75-78$ & 1.688 & 1.718 & 2.2 & & & \\
\hline
\end{tabular}

As shown in Figure 11, $\mathrm{CO}_{2}$ removal performance meets requirements for worst case sensor accuracy, even with conservatism for the Horiba analyzer accuracy. Values from the Boeing Analysis ${ }^{5}$ are shown as single points for comparison.

Using MCA analyzer values also results in $\mathrm{CO}_{2}$ removal performance meeting requirements for worst case sensor accuracy, even with conservatism for the MCA analyzer accuracy. Figure 12 shows a near overlap of sensor error bars occurs at Condition 2. For this condition, $\mathrm{CO}_{2}$ levels had not steadied out prior to changing the $\mathrm{CO}_{2}$ doser value for the next test, such that $\mathrm{CO}_{2}$ concentration was higher than its steady-state value.

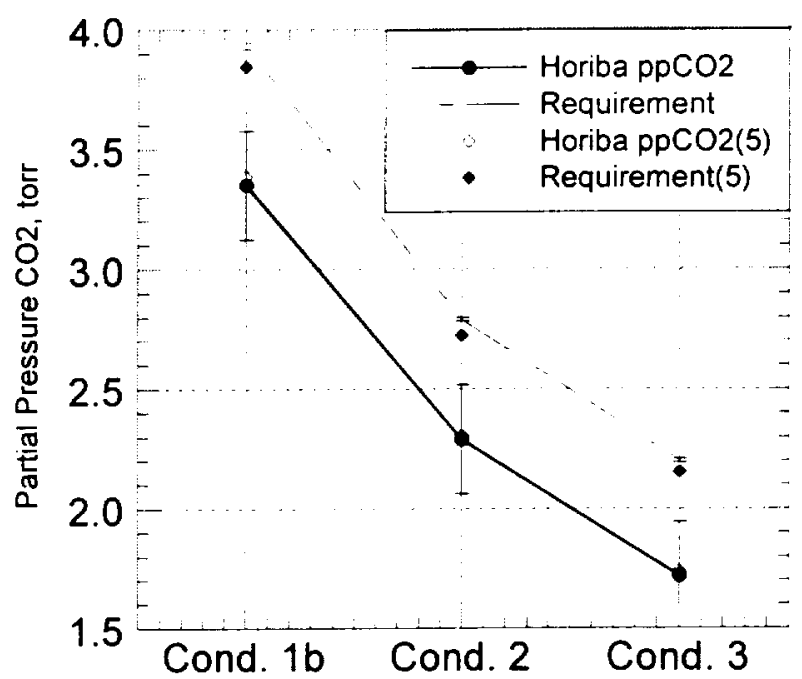

Figure 11. Error Analysis for Horiba Analyzer

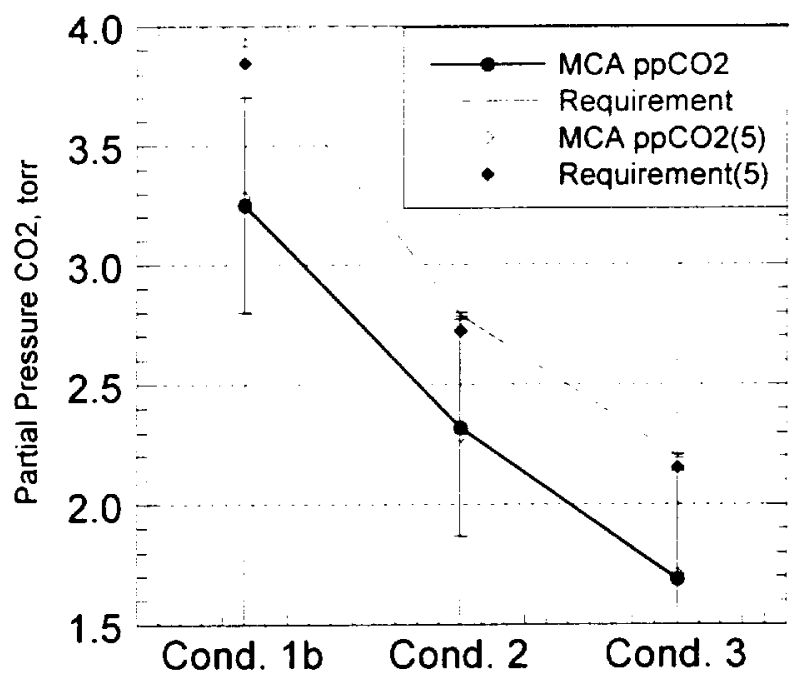

Figure 12. Error Analysis for MCA

\section{CONCLUSIONS}

With regards to the CDRA operation and performance, the Closed Hatch ECLSS Qualification test was highly successful. Operation of the CDRA was without software or hardware error, due in no small part to extensive prior 
regression testing at the $A R$ rack level. $\mathrm{CO}_{2}$ removal performance exceeded specifications for all three loading conditions, even with a conservative error analysis for the $\mathrm{CO}_{2}$ analyzers. The information obtained during this test provides valuable model correlation and reference data.

\section{CONTACT}

James C. Knox

Mail Stop FD21

Marshall Space Flight Center

Huntsville, AL 35812

Telephone: (256) 544-4887

E-mail: James.C.Knox@msfc.nasa.gov

\section{REFERENCES}

1. Environmental Control and Life Support (ECLS) Architecture Description Document, Volume 2, Book 2, Revision C, D684-10508-02-02, Boeing Defense and

Space Group, Houston, 1999

2. Sanders, Catherine, Test Readiness Review for USL Closed-Hatch ECLSS Test, Presented at the for USL Closed-Hatch ECLSS Test Readiness Review, Kennedy Space Flight Center, April 1999

3. Curtis, Robert, Post-Closed Hatch ECLSS CO2 Performance Analyses - Interim Report, Boeing Defense and Space Group, Huntsville Alabama, 1999

4. Prime Item Development Specification for United States Laboratory, International Space Station, S68329523J, Boeing Defense and Space Group, Huntsville Alabama, November 1997

5. Russell, Madison, Flight Article Closed Hatch $\mathrm{CO} 2$ Removal Test, 2-8265-MRR-01-00, Boeing Defense and Space Group, Huntsville Alabama, January 2000

6. MSFC Calibration Report on ECN M634722, Marshall Space Flight Center, Alabama, June 1999

7. Conversation with Bryan Pendegraft, MSFC Calibration Facility, May 9, 2000 